Proceedings

\title{
Characterization of Lactobacillus Brevis with Potential Probiotic Properties and Biofilm Inhibition Against Pseudomonas Aeruginosa ${ }^{\dagger}$
}

\author{
Vaishali Singh ${ }^{1}$, Suman Ganger ${ }^{2}$ and Shweta Patili,** \\ 1, 2, 3Department of Microbiology, Vivekanand Education Society's College of Arts, Science and Commerce, \\ Mumbai, - 400071, Maharashtra, India. \\ * Correspondence: shweta.patil@ves.ac.in \\ + Presented at the 1st International Electronic Conference on Microbiology, 2-30 November 2020; Available \\ online: https://ecm2020.sciforum.net/
}

Published: 2 November 2020

\begin{abstract}
Background: Probiotics are a live microbial supplement, which improves hosts health by maintaining intestinal microbiota. The evidence suggests that probiotics can be used as a therapeutic strategy to improve overall digestive health. Lactic acid bacteria strains have been extensively used as probiotics. (2) Method: To isolate lactic acid bacteria with probiotic potential from food samples. Probiotic properties such as tolerance to low $\mathrm{pH}$, bile, Sodium chloride, lysozyme, antibiotic susceptibility, cell surface hydrophobicity and antimicrobial activity were determined. (3) Results: Ten different isolates were examined to study their probiotic potential. In this study, Lactobacillus brevis was isolated, it showed most of the probiotic properties like $10 \%$ Sodium chloride tolerance, $1 \%$ bile tolerance, growth in $\mathrm{pH} 2$ and antimicrobial activity against $E$. coli, S. aureus, K. pneumoniae, and P. aeruginosa. Formation of biofilm by Klebsiella pneumoniae, and Pseudomonas aeruginosa also inhibited by cell free extracts of $L$. brevis, which reveals its therapeutic relevance. In addition, it was found to be stable at low temperature $\left(4^{\circ} \mathrm{C}\right) .(4)$ Conclusion: Based on the above-mentioned results of L. brevisit suggests that it has promising potential to be considered as 'Probiotic'. Further in vivo assessments could be carried out which will provide its dual role of prevention as well as use in therapy.
\end{abstract}

Keywords: Lactic acid bacteria; Probiotics; Lactobacillus brevis; probiotic properties; antibiofilm activity; pseudomonas aeruginosa

\section{Introduction}

The word 'probiotic' originated from Greek language 'pro-bios' which means 'for life'[1]. Probiotics are microbial cell preparations or components of microbial cells, when administered in adequate amounts; confer a beneficial effect on the health and well-being of the host. A good probiotic agent needs to be non-pathogenic, non-toxic, and resistant to gastric acid, adhere to gut epithelial tissue and produce antibacterial substances [2].

Since ancient times lactic acid bacteria (LAB) strains have been used as probiotics because of their health-promoting effects in the host [3]. These organisms have been widely reported to exert many beneficial effects, such as activation of the immune system, prevention of cancer cell growth, maintenance of mucosal integrity and presentation of an antagonistic environment for pathogens [4]. The inhibitory mechanisms of probiotic include production of antimicrobial compounds, like lactic acid, bacteriocin, cytokines and butyric acid, reduction of gut $\mathrm{pH}$ due to production of lactic $[5,6]$. Lactic acid bacteria (LAB) are characterized as gram-positive cocci or rods, aerotolerant, able to ferment carbohydrates for energy with the production of lactic acid[7]. Nowadays,attention is given 
in obtaining new probiotic bacterial strains from traditional foods and pharmaceutical industries. Globally, interest has been developed in the consumption of functional foods or nutraceuticals with potential probiotic microorganisms and the estimation of the global market is above US $\$ 28.8$ billion[8].

Lactobacillus brevis is a heterofermentative gram-positive organism, which could be isolated from milk, cheese, sauerkraut, sour dough, silage, mouth and intestinal tract of humans [9]. Due to its longterm use in various traditionally fermented food products, L. brevis has the GRAS status. L. brevis is not, typically used in probiotic products although O'Sullivan et al. (1992) [10], and Collins et al. (1998) [11], have mentioned L. brevis in a list of strains currently used in probiotic products. Furthermore, Kishi et al. (1996) [12]; have reported L. brevis strain as a potential probiotic. Pseudomonas aeruginosa is an important cause of infections, especially in immunocompromised hosts, it has numerous virulence factors and shows high resistance to antibacterial agents. It has natural resistance to many drugs, its ability to form biofilms, complex adherent structured microbial communities, etc [13]. Additionally, this pathogen is well known as food- and milk-spoilage microorganism showed an important concern in controlling these bacteria by new strategies have been considered by researchers [14]. In addition,Klebsiella pneumoniaeis one of the main causes of urinary tract infections (UTI), pneumonia, intra-abdominal infections etc. Due to their biofilm formation, they are more recalcitrant to antibiotics. Lactobacilli strains have been extensively studied in this regard as well because of their remarkable ability to inhibit the growth of pathogenic bacteria by producing bactericidal compounds [15].

The aim of this study is to screen, isolate and identify lactic acid bacteria from food samples. In addition, to characterize probiotic potential of the isolates and determine its biofilm inhibition activity formed by Pseudomonas aeruginosa and Klebsiella pneumoniae.

\section{Materials and Methods}

\subsection{Sample collection and Isolation of Lactic acid bacteria:}

Samples like milk, yoghurt, buttermilk, idli batter, sauerkraut were collected in a sterile container and stored at $4^{\circ} \mathrm{C}$ and plated out within 24 hours. Samples were isolated on Rogosa SL agar medium and plates were incubated under low oxygen conditions, at $27^{\circ} \mathrm{C}$ for 24 - 48 hours [16]. Single discrete colonies were picked from Rogosa SL agar plate and preliminary identification was carried out by performing gram staining, physiological and biochemical (catalase, oxidase, IMViC test, TSI) tests including sugar fermentation and gas production and isolation on HHD medium, referring Bergey's manual of systematic bacteriology Volume 2 [17]. After confirmation of lactic acid bacteria, the cultures were kept in MRS agar slant and stored at $4^{\circ} \mathrm{C}$.

\subsection{Determination of tolerance to sodium chloride, bile salt, low $\mathrm{pH}$ and lysozyme:}

For determination of sodium chloride tolerance, all the isolates were grown in MRS broth supplemented with different concentrations of sodium chloride ranging from $2 \%$ to $10 \%$ [18].The ability of the strains to tolerate bile salts was examined by observing the optimum growth by inoculating various isolates separately into MRS broth tubes supplemented with $0.2 \%-1 \%$ bile salts (Sodium taurocholate) [19]. For determination of growth at low $\mathrm{pH}$, the isolates were inoculated into MRS broth with varying $\mathrm{pH}$ ranging from 2.0 to 6.0 [20]. The broths were inoculated with overnight culture of the isolates and incubated at low oxygen conditions at $27^{\circ} \mathrm{C}$ for $24-48$ hours, bacterial growth was monitored by measuring the absorbance at $600 \mathrm{~nm}$. For lysozyme tolerance, cells were suspended in $60 \mathrm{mM}$ phosphate-buffer ( $\mathrm{pH} 6.2$ ) supplemented with $100 \mu \mathrm{g} / \mathrm{mL}$ of lysozyme and kept for 24 hours. The degree of cell lysis was measured spectrophotometrically by calculating the change in absorbance at $620 \mathrm{~nm}[21] . \%$ of survival rate $=[\mathrm{OD}$ after 24 hour $/$ OD at 0 hour] $\times 100 \ldots$ (1)

\subsection{Antibiotic susceptibility test:}

Antibiotic susceptibility testing was performed using the agar disk diffusion method. Antibiotics discs (Hi Media) were placed on MRS agar plates swabbed with 24 hour grown cultures. Antibiotic 
discs like Ampicillin, Ciprofloxacin, Azithromycin, Amikacin, Chloramphenicol, Gentamicin Erythromycin, Tetracycline and Vancomycin and were selected with known concentrations based on reviews of literature. The zones of inhibition were measured after incubation at low oxygen level in $27^{\circ} \mathrm{C}$ for 24 hours [20].

\subsection{Antimicrobial activity}

Antimicrobial activity of the isolates was determined by scrape and streak method [22] using indicator strains like Staphylococcus aureus, Bacillus subtilis, Pseudomonas aeruginosa, Klebsiella pneumoniaeand incubated for $18-24$ hours at $37^{\circ} \mathrm{C}$. Inhibition of the indicator strains were recorded near the streak of original strain.

\subsection{Cell Surface Hydrophobicity}

The in vitro cell surface hydrophobicity was determined by the bacterial adherence to hydrocarbon assay using the method of S. Klayruang et al [23]. Hydrophobicity was calculated as the percentage decrease in the optical density of the initial aqueous bacterial suspension due to cells partitioning into a hydrocarbon layer. The percentage of cell surface hydrophobicity $(\% \mathrm{H})$ of the strain adhering to $\mathrm{n}-\mathrm{Hexane}$ was calculated using the equation. $\% \mathrm{H}=[(\mathrm{Ao}-\mathrm{A}) / \mathrm{Ao}] \times 100 \ldots . .(2)$

\subsection{Antibiofilm activity}

Crystal violet (Tube method)was carried out for assessing the biofilm inhibition using Pseudomonas aeruginosa and Klebsiella pneumoniae. The culture tube without cell free supernatant served as control. The results were expressedas the percentage of biofilm inhibition [24]. \%I = [(Absorbance control - Absorbance sample)/ Absorbance Sample] $\times 100 \ldots$ (3) where I (\%) is the percentage of biofilm inhibition, absorbance control is the optical density in control and absorbance sample is the optical density in sample with cell free supernatant.

\subsection{Stability at two different temperatures:}

The stability of the selected strain was studied by exposing it to two temperatures $\left(4^{\circ} \mathrm{C}\right.$ and 27 ${ }^{\circ} \mathrm{C}$ ) and evaluating the viability of the cells by the pour plate method into MRS media.

\subsection{Stability in ice cream:}

Ice creamwas purchased locally and was used to study the stability of the selected isolate. Ice creamwas melted by keeping in room temperature into which the isolate was inoculated. After homogenization, the DAY 0 count was determined by the pour plate method into MRS agar. Ice creamwas kept in the refrigerator for 7 days at $4^{\circ} \mathrm{C}$. After which the viability of the cells was determined and compared with the initial count.

\section{Results}

\subsection{Screening, Isolation and Identification of Lactic acid Bacteria:}

Ten isolates namely, MI, MII, BMI, SII, SIV, SIV2, IB1, IB2, IB3 and YK, were selected for their probiotic potential. All isolates were gram positive while morphology observed was short rods, cocci in clusters and rods. In addition, the isolates were catalase, oxidase and IMViC test negative. Six isolates MI, BMI, IB1, IB2, IB3 and YK were found to be homofermentative whereas four isolates were heterofermentative.

\subsection{Tolerance to sodium chloride, bile salts, low $\mathrm{pH}$ and lysozyme:}

Comparison analysis of all isolates is shown in figure 1: (a) and (b). Survival rates of selective isolates SIV2, SII and IB2 for $100 \mu \mathrm{g} / \mathrm{ml}$ of lysozyme were $49.50 \%, 58.00 \%$ and $77.00 \%$ respectively. Out of the ten isolates which were studied for their probiotic properties, isolate SII matches with 
probiotic criteria to a promising extent.It was able to tolerate $10 \% \mathrm{NaCl}$ and grow at $\mathrm{pH}$ range $2.0-$ 6.0.

\subsection{Antibiotic susceptibility test:}

Isolates showed different susceptibility patterns. Isolate SIV, SIV2, SII, IB2 and IB3 were susceptible to ampicillin $(10 \mu \mathrm{g})$, and all were resistant to vancomycin $(30 \mu \mathrm{g})$. SII isolate showed resistance towards amikacin $(30 \mu \mathrm{g})$, ciprofloxacin $(5 \mu \mathrm{g})$, gentamicin $(10 \mu \mathrm{g})$ and vancomycin $(30 \mu \mathrm{g})$ and very less sensitivity towards ampicillin $(10 \mu \mathrm{g})$ and tetracycline $(30 \mu \mathrm{g})$ about 3-5 $\mathrm{mm}$ zone of inhibition.

\subsection{Antagonistic activity against pathogens:}

Isolate SII showed inhibitory effect towards all indicator strains such as E. coli, K. pneumoniae, S. aureus, $P$. aeruginosa, suggesting some antimicrobial compounds were produced which inhibited the growth of indicator strains. This method had an advantage over other methods like agar well diffusion assay, as some antimicrobialcompounds are produced in very small quantities and may require more quantity to diffuse properly into the medium.

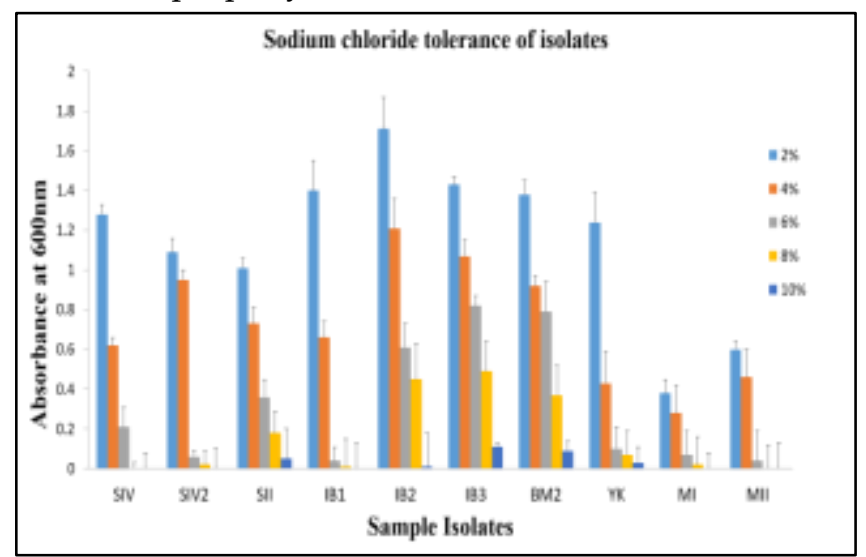

(a)

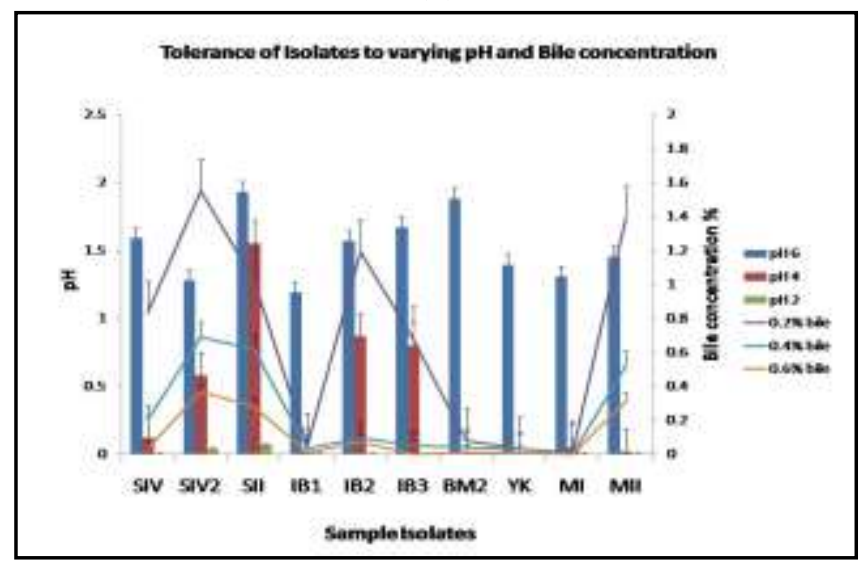

(b)

Figure 1. (a) Sodium chloride tolerance of isolates at different concentrations; (b) bile salt and $\mathrm{pH}$ tolerance of isolates at different concentrations of bile and $\mathrm{pH}$ values respectively.

\subsection{Cell Surface Hydrophobicity}

The hydrophobicity percentage of the isolate SII to n-hexane was found to be $5.03 \%$.

\subsection{Antibiofilm activity of isolate SII}


It was observed that tubes with cell free extracts of SII have potential to inhibit biofilm formation. Maximum biofilm inhibition of $52.63 \%$ of Pseudomonas aeruginosa was observed. While on Klebsiella pneumoniae biofilm the inhibition activity was found to be $22.2 \%$.

\subsection{Stability of L.brevis at two different temperatures:}

The initial day count of L. brevis kept at $4^{\circ} \mathrm{C}$ and $27^{\circ} \mathrm{C}$ was found to be $2.89 \times 10^{7} \mathrm{cfu} / \mathrm{ml}$. After 7 days, count of the isolate kept at $27^{\circ} \mathrm{C}$ was found to be zero, while $56.13 \%$ reduction in the viability of $L$. brevis kept at $4^{\circ} \mathrm{C}$ was observed. Thus, suggesting that isolate was more stable at $4^{\circ} \mathrm{C}$ than at $27^{\circ} \mathrm{C}$.

\subsection{Stability of L.brevis in Ice-cream:}

The DAY 0 count of L. brevis was found to be $4.3 \times 10^{5} \mathrm{cfu} / \mathrm{ml}$ and DAY 7 cell viability was found to be $3.1 \times 10^{5} \mathrm{cfu} / \mathrm{ml}$. Thus, suggesting that $L$. brevis is more stable in dairy products which are stored at lower temperatures with $27.90 \%$ of reduction in viability.

\subsection{Molecular and genetic analysis of SII:}

Using $16 \mathrm{~S}$ rRNA technique an identification of isolate SII was carried out at Saffron Lifescience Antalia, Bilimora. District -Navsari (Gujrat) and it was found to be Lactobacillus brevis ATCC 14869 Accession no. NR_116238.1

\section{Discussion and Conclusion}

Ten isolates were evaluated for their probiotic potential, out of which one isolate SII gave encouraging results and was considered for further evaluation like antibiofilm activity, stability testing etc.

In the present study, Lactobacillus brevis ATCC 14869 was isolated from a sauerkraut sample, whichwas identified by $16 \mathrm{~S}$ rRNA sequencing. L. brevis survival and growth at low $\mathrm{pH}(\mathrm{pH} 2-6)$ and in presence of bile $(0.2-1 \%)(\mathrm{w} / \mathrm{v})$ suggest that it can survive in extreme condition of the intestinal tract. Being resistant to low $\mathrm{pH}$ is one of the major selection criteria for probiotic strains[25]. Regarding bile salt tolerance of probiotic lactobacilli, their survival in presence of $0.3 \%$ bile salt is physiologically significant, since the bile salts at such a level are present normally in the human intestine [26]. L. brevis could tolerate $1-10 \%(\mathrm{w} / \mathrm{v}) \mathrm{NaCl}$ concentration. $\mathrm{NaCl}$ adapted isolates can help to survive in simulated gastric fluid. Probiotic bacteria are exposed to saliva in the oral cavity that contains lysozyme and electrolytes and thus, lysozyme tolerance is one of the criteria in probiotic selection.

L. brevis showed resistance towards a broad range of antibiotics suggesting that it can be used in combination with antibiotics for treatment of certain infections which may aid in rapid recovery of the healthier microbial balance. The results were as expected as lactobacilli are known to be naturally resistant toward several antibiotics [27]. L. brevis showed antimicrobial activity against some of the indicator strains indicating that they produce antimicrobial compounds [28].

Biofilm production by $P$. aeruginosahas been consideredas an important determinant of its pathogenicity. Maximum biofilm inhibition of $52.63 \%$ of Pseudomonas aeruginosa was observed.Antimicrobial compounds in the cell free supernatant were believed to halt the growth of the pathogen and even cause death in the cells, rendering the aggregation of cells to form the biofilm unsuccessful. Thus, identification of such LAB strains that have antibiofilm activity would be essential to include these as alternatives in control of biofilms [29].In a study reported by D Shorkri,et.al [13], inhibitory effects of lactobacilli against $P$. aeruginosa and their biofilm formation were investigated.

Cell surface hydrophobicity of L. brevis was about 5.03\%. Lack of correlation between hydrophobicity and bacterial adhesion has been reported where strains with high hydrophobicity exhibited lower adhesion to human cell line[30]. Thus, hydrophobicity may be helpful in adhesion, but it is obviously not a prerequisite for a strong adherence capacity. Stability of L. breviswas found 
to be higher in lower temperatures as well as in dairy products like ice cream, which is stored $4^{\circ} \mathrm{C}$ as compared to other temperatures. In a study, it is reported that L. brevisATCC 8287 was a promising strain as a probiotic supplement in dairy products [28]. Thus, from the in vitro methods performed and results discussed it suggests that L. brevis ATCC 14869 has the promising potential to be considered as a 'Probiotic', and to the best of knowledge there is no work reported with L. brevis ATCC 14869 as a Probiotic, hence; it can be additional strain which can be considered for probiotics. However further in vivo trials are needed to determine whether it benefits human health.

A key conclusion from this research is that potential probiotic candidates can be isolated from dairy food, fermented vegetables etc. and they show a promising potential for further development as a novel probiotic. In future, research efforts can be carried outto exploit other potential probiotic properties of these strains so that it can be used in the medical field as well as their products can be used in the pharmaceutical industry.

Author Contributions: S.G. and S.P. conceived of the presented idea. V.S. carried out the experiment. S.G. and S.P. verified the analytical methods and supervised the findings of this work. All authors discussed the results and contributed to the final manuscript.

Acknowledgements: Authors are thankful to Vivekanand Education Society's College of Arts, Science and Commerce - Central Instrumentation Facility (funded by DST-FIST grants) for their infrastructure and the teaching and non-teaching staff of the Microbiology department for their constant support.

Conflicts of Interest: The authors declare that there are no conflicts of interest.

\section{References}

1. Gismondo, M., Drago, L., \& Lombardi, A. "Review of Probiotics Available to Modify Gastrointestinal Flora." Antimicrobics Infectious Diseases Newsletter, vol. 17, no. 10, (1998), pp. 79. doi: 10.1016/s09248579(99)00050-3.

2. Sekhon BS and Jairath S. Prebiotics, probiotics, and synbiotics: An Overview. Journal of Pharmaceutical Education and Research vol. 1 no. 2, (2010), pp. 19-25.

3. Foligné, B., Daniel, C., \& Pot, B. Probiotics from research to market: The possibilities, risks and challenges. Current Opinion in Microbiology, vol. 16 no. 3, (2013), pp. 284-292. doi: 10.1016/j.mib.2013.06.008.

4. Ouwehand, A. C., Salminen, S., \& Isolauri, E. “Probiotics: An Overview of Beneficial Effects." Lactic Acid Bacteria: Genetics, Metabolism and Applications, (2002), pp. 279-289. doi: 10.1023/A:1020620607611.

5. Ohara, Ann M., and Fergus Shanahan. "Mechanisms of Action of Probiotics in Intestinal Diseases." The Scientific World JOURNAL, vol. 7, (2007), pp. 31-46. doi: 10.1100/tsw.2007.26.

6. Ng SC, Hart AL, Kamm MA, Stagg AJ and Knight SC. Mechanisms of action of probiotics: Recent advances. Inflammatory Bowel Diseases vol. 15 no. 2, (2009), pp. 300-310. doi: 10.1002/ibd.20602.

7. Caplice, E. "Food fermentations: role of microorganisms in food production and preservation." International Journal of Food Microbiology, vol. 50, no. 1-2, (1999), pp. 131-149. doi: 10.1016/S0168-1605(99)00082-3.

8. Quinto, E.J., Jimenez, P., Caro, I., Tejero, J., Mateo, J. and Girbes, T. “Probiotic lactic acid bacteria: A review”. Food and NutritionSciences vol.5, (2014), pp. 1765-1775. doi: 10.4236/fns.2014.518190

9. Kandler, O., Weiss, N. Regular, nonsporing gram-positive rods. Bergey'sManual of Systematic Bacteriology, vol. 2. Williams \& Wilkins, Baltimore, (1986), pp. $1208-1260$.

10. O'Sullivan, M.G., Thornton, G., O'Sullivan, G.C., Collins, J.K. Probiotic bacteria: myth or reality? Trends in Food Science and Technology 3,(1992), pp 309 - 314. doi:10.1016/S0924-2244(10)80018-4.

11. Collins, J.K., Thornton, K., Sullivan, G.O. Selection of probiotic strains for human applications. International Dairy Journal 8, (1998), pp 487 - 490doi: 10.1016/S0958-6946(98)00073-9.

12. Kishi, A., Kazuko, U., Matsubara, Y., Okuda, C., Kishida, T. Effect of oral administration of Lactobacillus brevis subsp. Coagulans on interferon-a producing capacity of humans. Journal of the American College of Nutrition vol. 15, no. 4, (1996), pp. 408 - 412. doi: 10.1080/07315724.1996.10718617. 
13. Shokri, D., Khorasgani, M. R., Mohkam, M., Fatemi, S. M., Ghasemi, Y., \& Taheri-Kafrani, A. (2017). The Inhibition Effect of Lactobacilli Against Growth and Biofilm Formation of Pseudomonas aeruginosa. Probiotics and Antimicrobial Proteins, 10(1), 34-42. doi:10.1007/s12602-017-9267-9

14. Chatterjee M, Anju C, Biswas L, Kumar VA, Mohan CG, Biswas R. Antibiotic resistance in Pseudomonas aeruginosa and alternative therapeutic options. International Journal of Medical Microbiology vol. 306, no. 1, (2015), pp. 48-58.doi: 10.1016/j.ijmm.2015.11.004

15. Tri Yudani Mardining Raras, Alif Firman Firdausy, Intan Rakhma Kinanti, and Noorhamdani Noorhamdani, Anti-Biofilm Activity of Lactic Acid Bacteria Isolated from Kefir Against MultidrugResistant Klebsiella pneumoniae, J Pure Appl Microbiol., 2019; 13(2): 983-992 doi: 10.22207/JPAM.13.2.35

16. Hartemink, R, et al. "LAMVAB-A New Selective Medium for the Isolation of Lactobacilli from Faeces." Journal of Microbiological Methods, vol. 29, no. 2, (1997), pp. 77-84.

17. Sneath, P. H. E., Mair, N. S. E., Sharpe, M. E. E., \& Holt, J. G. E. Bergeys Manual of Systematic Bacteriology; Volume 2. Baltimore, MD, Williams \& Wilkins. (1986).

18. Ouwehand, Arthur, and Satu Vesterlund. "Antimicrobial Components from Lactic Acid Bacteria." Lactic Acid Bacteria, 2004.

19. Valdez, Graciela Font De, and MaríaPía Taranto. "Probiotic Properties of Lactobacilli: Cholesterol Reduction and Bile Salt Hydrolase Activity." Food Microbiology Protocols, (2001) pp.173-181. doi: 10.1385/1-59259-029-2:173.

20. Prabhurajeshwar, Chidre, and Revanasiddappa Kelmani Chandrakanth. "Probiotic Potential of Lactobacilli with Antagonistic Activity against Pathogenic Strains: An in Vitro Validation for the Production of Inhibitory Substances." Biomedical Journal, vol. 40, no. 5, (2017), pp. 270-283. doi: 10.1016/j.bj.2017.06.008.

21. Kimoto-Nira, H., Suzuki, C., Kobayashi, M., \& Mizumachi, K. “Different Growth Media Alter the Induction of Interleukin 12 by a Lactococcus Lactis Strain." Journal of Food Protection, vol. 71, no. 10, (2008), pp. 21242128. doi: 10.4315/0362-028x-71.10.2124.

22. Gillies, R. R., and J. R. W. Govan. “Typing of Pseudomonas Pyocyanea by Pyocine Production.” The Journal of Pathology and Bacteriology, vol. 91, no. 2, (1966), pp. 339-345. doi: 10.1002/path.1700910207.

23. Klayraung, Srikanjana. "Probiotic properties of Lactobacilli Isolated from Thai Traditional Food." Scientia Pharmaceutica, vol. 76, no. 3, (2008), pp. 485-503. doi: 10.3797/scipharm.0806-11.

24. Mathkhury HJF, Ali AS, Ghafil JA “Antagonistic Effect of Bacteriocin against Urinary Catheter Associated Pseudomonas Aeruginosa Biofilm." North American Journal of Medical Sciences, (2011), pp. 367-370. doi: 10.4297/najms.2011.3367.

25. Chou, L., \&amp; Weimer, B. Isolation and Characterization of Acid- and Bile-Tolerant Isolates from Strains of Lactobacillus acidophilus. Journal of Dairy Science,vol. 82, no. 1, (1999), pp. 23-31. doi: 10.3168/jds.S00220302(99)75204-5.

26. Prasad, J. Gill, H., Smart, J., \& Gopal, P. K. "Selection and Characterisation of Lactobacillus and Bifidobacterium Strains for Use as Probiotics." International Dairy Journal, vol. 8, no. 12, (1998), pp. 9931002. 1.doi: 10.1016/S0958-6946(99)00024-2.

27. Charteris, W.P., Kelly, P.M., Morelli, L., Collins, J.K. “Antibiotic susceptibility of potentially probiotic Lactobacillus species." Journal of Food Protection 61, (1998), pp.1636-1643. doi: 10.4315/0362-028x61.12.1636

28. Rönkä, Elina.,Erja M., Maria S., Merja RK., Johannes A., Airi P. “Probiotic and Milk Technological Properties of Lactobacillus Brevis." International Journal of Food Microbiology, vol. 83, no. 1, (2003), pp. 6374. doi: 10.1016/s0168-1605(02)00315-x

29. Fang, Fang, et al. "Characterization of a Lactobacillus Brevis Strain with Potential Oral Probiotic Properties." BMC Microbiology, vol. 18, no. 1, (2018). doi: 10.1186/s12866-018-1369-3.

30. Mathara, J., Schillinger, U., Guigas, C., Franz, C., Kutima, P., Mbugua, S. Holzapfel, W. "Functional Characteristics of Lactobacillus Spp. from Traditional Maasai Fermented Milk Products in Kenya." International Journal of Food Microbiology, vol. 126, no. 1-2, (2008), pp. 57-64. doi: 10.1016/j.ijfoodmicro.2008.04.027

Publisher's Note: MDPI stays neutral with regard to jurisdictional claims in published maps and institutional affiliations. 
(C) 2020 by the authors. Submitted for possible open access publication under the terms and conditions of the Creative Commons Attribution (CC BY) license (http://creativecommons.org/licenses/by/4.0/). 